\title{
Penyusunan Model Bangkitan Pergerakan Angkutan Barang di Provinsi Kalimantan Timur
}

\section{Development of Freight Trip Generation Model in East Kalimantan Province}

\author{
Triana Sharly P. Arifin ${ }^{1, \text { a) }}$, Budi Haryanto ${ }^{1, b)}$ \& Utari Nur Ramadhani ${ }^{1, \mathrm{c}}$ \\ 1)Teknik Sipil, Universitas Mulawarman, Samarinda \\ Koresponden : ${ }^{a)}$ triana.sharly@gmail.com, ${ }^{b}$ budiharyanto7951@gmail.com \& \\ c)tarirmdhn@gmail.com.
}

\begin{abstract}
ABSTRAK
Kalimantan Timur merupakan provinsi dengan luas wilayah yang besar. Hal ini kemudian menyebabkan tingkat pergerakan angkutan barang di Provinsi Kalimantan Timur besar pula. Pola pergerakan barang di Provinsi Kalimantan Timur dipengaruhi oleh potensi sumber daya alamnya. Kurangnya perhatian yang diberikan terhadap transportasi barang dalam sistem transportasi di Indonesia khususnya Kalimantan Timur, menyebabkan harga barang yang sangat bervariasi dari tingkat produsen hingga ke tingkat konsumen. Penelitian ini bertujuan untuk menganalisis model bangkitan pergerakan transportasi angkutan barang dalam Provinsi Kalimantan Timur serta jumlah pergerakannya pada masa yang akan datang. Metode yang digunakan adalah analisis model korelasi berbasis zona metode langkah demi langkah tipe 1. Pemodelan dilakukan dengan menggunakan bantuan aplikasi statistik SPSS 22. Dari Hasil pemodelan angkutan barang dalam Provinsi Kalimantan Timur, didapatkan model bangkitan yaitu $\mathrm{Y}=77.041,534-0,001 \mathrm{X}_{1}-0,397 \mathrm{X}_{5}+102,167 \mathrm{X}_{12}+0,035 \mathrm{X}_{13}+$ $11,399 \mathrm{X}_{14}-8,407 \mathrm{X}_{16}$ Dengan nilai koefien korelasi $(\mathrm{R})$ sebesar 0,977 dan nilai koefisien determinasi $\left(\mathrm{R}^{2}\right)$ sebesar 0,954 .
\end{abstract}

Kata Kunci : manajemen infrastruktur jalan, bangkitan pergerakan, angkutan barang, pemodelan transportasi.

\section{PENDAHULUAN}

Transportasi atau pergerakan angkutan barang merupakan salah satu kegiatan yang sangat penting dalam kehidupan masyarakat. Transportasi angkutan barang berperan penting dalam pembangunan yang merupakan urat nadi kehidupan politik, ekonomi, sosial budaya, dan pertahanan-keamanan. Indonesia memiliki letak geografis yang strategis namun memiliki jumlah penduduk dan tingkat pertumbuhan penduduk yang tinggi. Hal ini kemudian menyebabkan tingkat kebutuhan masyarakat akan barang meningkat hampir di seluruh provinsi di Indonesia, bahkan sampai ke kabupaten/kota. Besarnya pergerakan angkutan barang di Indonesia dapat direpresentasikan dengan Matriks Asal-Tujuan (MAT) ataupun dengan diagram garis keinginan (desire line).

Jaringan Jalan, sebagai aset infrastruktur vital, harus dikelola dengan baik. Oleh karena itu, Jaringan Jalan harus dikelola dengan baik sesuai prinsip Manajemen Aset Infrastruktur. Salah satu prinsip dasar Manajemen Aset Infrastuktur adalah infrastruktur harus disediakan untuk memenuhi kebutuhan infrastruktur atau permintaan infrastruktur. Jadi pengembangan Jaringan Jalan harus didasarkan pada Permintaan Lalu-Lintas (Suprayitno \& Soemitro 2018). 
Untuk keperluan operasi jalan, jaringan jalan harus disusun dalam struktur jaringan yang bagus kedalam klasifikasi fungsi dan status dan klas jalan (Anggita, Arifin \& Dhonanto 2015; Dhonanto, Arifin \& Anggita 2015; Mutiawati \& Suprayitno 2018). Oleh karena itu Permintaan Perjalanan harus selalu bisa diprakirakan dengan baik dalam bentuk Model Permintaan Transportasi. Pemodelan Permintaan Transportasi untuk Perjalanan Orang telah banyak dibahas (Amijaya \& Suprayitno 2018; Praditya \& Suprayitno 2018). Kemajuan penelitian Bangkitan Perjalanan Orang sudah sampai pada tataran mengukur karakteristik tingkat ketepatan model dikaitkan dengan nilai koefisien determinasi (Suprayitno \& Ratnasari 2017; Ziantono \& Suprayitno 2018). Sebaliknya, Model Transportasi untuk Angkutan Barang baru dibahas secara terbatas.

Kalimantan Timur merupakan provinsi dengan total luas wilayah terbesar ketiga di Indonesia setelah Papua dan Kalimantan Tengah. Luas wilayah Provinsi Kalimantan Timur sekarang kurang lebih 127.346,92 $\mathrm{km}^{2}$. Pola pergerakan barang di Provinsi Kalimantan Timur dipengaruhi oleh potensi sumber daya alamnya. Dengan wilayah yang cukup besar dan kondisi geografisnya kemudian muncul masalah transportasi barang di Provinsi Kalimantan Timur. Dalam perencanaannya, perlu disiapkan strategi rencana aksi yang sistematis, logis, kondusif, tersosialisasi yang dilakukan secara periodik dan sinambung, seperti penentuan jaringan jalan lintas angkutan barang/kargo (Anggita, Arifin \& Dhonanto 2015; Dhonanto, Arifin \& Anggita 2015). Metoda Pemodelan Perjalanan Angkutan Barang sudah pernah dilakukan untuk Kota Surabaya (Suprayitno 1999), akan tetapi metoda tersebut tidak cocok untuk dipakai dalam kasus Provinsi Kalimantan Timur. Oleh karena itu dalam penelitian ini dilakukan analisis model bangkitan pergerakan angkutan barang dalam Provinsi Kalimantan Timur. Analisis model ini diharapkan dapat menjadi acuan untuk perencanaan sistem transportasi yang kemudian dapat dijadikan dasar rencana tata ruang wilayah Provinsi Kalimantan Timur baik dalam jangka pendek maupun jangka panjang serta peningkatan kapasitas jalan lintas provinsi di Kalimantan Timur.

\section{STUDI PUSTAKA}

Bangkitan pergerakan (trip generation) adalah tahapan pemodelan yang memperkirakan jumlah pergerakan yang berasal dari suatu zona atau tata guna lahan dan jumlah pergerakan yang tertarik ke suatu tata guna lahan atau zona (Tamin, 2000).

Hasil keluaran dari perhitungan bangkitan lalu lintas berupa jumlah kendaraan, orang, atau angkutan barang per satuan waktu, misalnya kendaraan/jam. Kita dapat dengan mudah menghitung jumlah orang atau kendaraan yang masuk atau keluar dari suatu luas tanah tertentu dalam satu hari (atau satu jam) untuk mendapatkan bangkitan pergerakan.

Transportasi barang dalam sistem transportasi di Indonesia cenderung dibatasi ruang geraknya dibandingkan dengan transportasi penumpang, hal ini mengakibatkan pengiriman barang tertunda beberapa saat dan akhirnya menyebabkan biaya transportasi menjadi tinggi karena banyak waktu terbuang percuma. Dalam transportasi barang dikenal istilah pengangkutan yang merupakan kegiatan memindahkan barang dari suatu tempat ke tempat yang lain. Sebagai suatu kegiatan jasa dalam memindahkan barang, pengangkutan berperan sekali dalam menciptakan pola distribusi barang yang dinamis guna meningkatan perekonomian wilayah.

Pada perencanaan transportasi, salah satu langkah yang harus kita lalui adalah menganalisis setiap data dan informasi yang relevan sebagai landasan untuk memprediksi apa yang akan terjadi pada masa yang akan datang. Data dan informasi ini bisa berupa data sekunder, yaitu data yang sudah tersusun yang didapat dari instansi atau badan-badan terkait, namun bisa pula berupa data primer yaitu data atau informasi yang diperoleh dari pengamatan langsung di lapangan atau dunia nyata. 
Dalam proses untuk mendapatkan pemodelan sebaran pergerakan terdapat beberapa metode yang dapat dilakukan, yaitu dengan metode konvensional dan metode tidak konvensional (Tamin, 2000).

Tujuan dasar tahap bangkitan pergerakan adalah menghasilkan model hubungan yang mengaitkan parameter tata guna lahan dengan jumlah pergerakan yang menuju ke suatu zona atau jumlah pergerakan yang meninggalkan suatu zona. Zona asal dan tujuan pergerakan biasanya juga menggunakan istilah trip end.

Dilakukan usaha untuk mendapatkan hubungan linear antara jumlah pergerakan yang dibangkitkan atau tertarik oleh zona dan ciri sosio-ekonomi rata-rata pada setiap zona. Dalam melakukan analisis bangkitan pergerakan dengan menggunakan model analisis-regresi berbasis zona, terdapat tiga metode analisis yang dapat digunakan, yaitu sebagai berikut :

1. Metode Analisis langkah-demi-langkah Tipe 1

2. Metode Analisis langkah-demi-langkah Tipe 2

3. Metode Coba-Coba

\section{A. Analisis Korelasi}

Secara sederhana, korelasi dapat diartikan sebagai hubungan. Namun, ketika dikembangkan lebih jauh, korelasi tidak hanya dapat dipahami sebatas pengertian tersebut. Korelasi merupakan salah satu teknik analisis dalam statistik yang digunakan untuk mencari hubungan antara dua buah variabel (Irianto, 2014).

Terdapat bermacam-macam teknik statistik korelasi yang dapat digunakan untuk menguji hipotesis asosiatif. Teknik korelasi mana yang akan dipakai tergantung pada jenis data yang akan dianalisis. Berikut ini dikemukakan berbagai teknik statistik korelasi yang digunakan untuk menguji hipotesis asosiatif. Untuk data nominal dan ordinal digunakan statistik Non-parametris dan untuk data interval dan ratio digunakan statistik Parametris (Irianto, 2014).

Uji korelasi Product Moment (Pearson) merupakan salah satu dari teknik korelasi yang sangat populer dan sering digunakan oleh mahasiswa dan para peneliti. Korelasi ini dikemukakan oleh Karl Pearson pada tahun 1990. Kegunaannya untuk mengetahui derajad hubungan antara variabel bebas (independent) dengan variabel terikat (dependent) (Irianto, 2014).

Adapun rumus untuk mendapatkan nilai $\mathrm{r}$ dari uji korelasi Pearson dapat dilihat pada persamaan sebagai berikut :

$$
r_{X Y}=\frac{n\left(\sum X Y\right)-\left(\sum X\right) \cdot\left(\sum Y\right)}{\sqrt{\left\{n \sum X^{2}-\left(\sum X\right)^{2}\right\} \cdot\left\{n \cdot \sum Y^{2}-\left(\sum Y\right)^{2}\right\}}}
$$

$$
\begin{aligned}
& \text { Keterangan : } \\
& r_{X Y}=\text { Nilai koefisien korelasi Pearson } \\
& \mathrm{n} \quad=\text { Banyak data } \\
& \sum X Y=\text { Jumlah hasil kali nilai variabel } \mathrm{X} \text { dan } \mathrm{Y} \\
& \sum \mathrm{X}=\text { Jumlah nilai variabel } \mathrm{X} \\
& \sum \mathrm{Y}=\text { Jumlah nilai variabel } \mathrm{Y} \\
& \sum \mathrm{X}^{2}=\text { Jumlah kuadrat nilai variabel } \mathrm{X} \\
& \sum \mathrm{Y}^{2}=\text { Jumlah kuadrat nilai variabel } \mathrm{Y}
\end{aligned}
$$


Uji korelasi Spearman digunakan untuk menguji signifikan atau tidaknya hubungan antara dua atau lebih variable berskala ordinal. Korelasi ini ditemukan oleh Spearman, sehingga disebut juga sebagai Korelasi Spearman. Korelasi ini disebut sebagai korelasi bertingkat, korelasi berjenjang, korelasi berurutan atau korelasi berpangkat (Irianto, 2014).

Adapun rumus daripada uji Korelasi Spearman dapat dilihat pada persamaan antara lain sebagai berikut :

$$
r_{s}=1-\frac{6 b^{2}}{N^{3}-N}
$$

Keterangan :

$$
\begin{aligned}
& \mathrm{r}_{\mathrm{s}}=\text { Nilai korelasi spearman } \\
& \mathrm{b}=\text { Jumah kuadrat dari perbedaan data } \\
& \mathrm{N}=\text { Banyak data }
\end{aligned}
$$

Untuk melihat seberapa besar tingkat pengaruh variabel independen terhadap variabel dependen secara parsial digunakan koefisien determinasi. Koefisien determinasi merupakan kuadrat dari koefisien korelasi sebagai ukuran untuk mengetahui kemampuan dari masingmasing variabel yang digunakan. Koefisien determinasi menjelaskan proporsi variasi dalam variabel dependen $(\mathrm{Y})$ yang dijelaskan oleh hanya satu variabel independen (lebih dari satu variabel bebas: $\mathrm{Xi}$; $\mathrm{i}=1,2,3,4$, dst.) secara bersama-sama (Sugiyono, 2011). Rumus koefisien determinasi dapat dilihat seperti dibawah ini :

$$
K d=R^{2} \times 100 \%
$$

Dimana:

$$
\begin{aligned}
& \mathrm{Kd}=\text { Koefisien determinasi } \\
& \mathrm{R}^{2}=\text { Nilai kuadrat dari koefisien korelasi }
\end{aligned}
$$

Kriteria untuk analisis koefisien determinasi adalah :

a. Jika Kd mendekati nol (0), berarti pengaruh variabel independen terhadap variabel dependen lemah.

b. Jika Kd mendekati angka satu (1), berarti pengaruh variabel independen terhadap variabel dependen kuat.

Harga $\mathrm{R}$ yang diperoleh sesuai dengan variasi yang dijelaskan masing-masing variabel yang tinggal dalam regresi. Hal ini mengakibatkan variasi yang dijelaskan penduga yang disebabkan oleh variabel yang berpengaruh saja (yang bersifat nyata).

Uji $\mathrm{F}$ digunakan untuk menguji pengaruh variabel bebas secara bersamaan terhadap variabel terikat (Irianto, 2014) :

$$
F_{\text {hitung }}=\frac{R^{2} /(\mathrm{k}-1)}{\left(1-R^{2}\right) /(\mathrm{n}-\mathrm{k}-1)}
$$

Keterangan :

$\mathrm{F} \quad=$ Pendekatan distribusi Probabilitas Fischer

$\mathrm{R}^{2} \quad=$ Koefisien determinasi

$\mathrm{k} \quad=$ Jumlah variabel bebas

$\mathrm{n} \quad=$ Banyak sampel

\section{B. Analisis Regresi}

Apabila terdapat dua variabel atau lebih, sudah sewajarnya kalau kita ingin mempelajari bagaimana variabel-variabel itu berhubungan. Hubungan yang diperoleh biasanya dinyatakan dalam persamaan matematik yang menyatakan hubungan fungsional antara variabel-variabel. 
Analisis yang menyangkut masalah ini dinamakan analisis regresi. Hubungan fungsional antara satu variabel predikator dengan satu variabel kriterium disebut analisis regresi tunggal, sedangkan hubungan fungsional yang lebih dari satu variabel disebut analisis regresi ganda.

Pada analisis regresi terdapat 2 metode yang sering digunakan, antara lain sebagai berikut :

a. Analisis Regresi Tunggal

b. Analisis Regresi Berganda

Analisis regresi tunggal digunakan untuk mendapatkan hubungan matematis dalam bentuk suatu persamaan antara variabel bebas tunggal dengan variabel tak bebas tunggal (Tamin 2000). Analisis regresi tunggal hanya memiliki satu peubah $X$ yang dihubungkan dengan satu peubah tidak bebas Y. Bentuk umum dari persamaan analisis regresi tunggal dapat dilihat pada persamaan, sebagai berikut :

$$
\mathrm{Y}=\mathrm{a}+\mathrm{bx}
$$

Keterangan :

$\mathrm{Y}=$ Variabel tak bebas

$\mathrm{X}=$ Variabel bebas

a $\quad$ Parameter intersep

$\mathrm{b}=$ Parameter koefisien regresi variabel bebas

Regresi linier berganda adalah analisis regresi yang menjelaskan hubungan antara peubah respon (variabel dependen) dengan faktor-faktor yang mempengaruhi lebih dari satu prediktor (variabel independen) (Tamin,2000). Dalam permodelan bangkitan pergerakan, metode analisis regresi linier berganda yang paling sering digunakan baik dengan zona dan data rumah tangga atau individu. Metode analisis regresi linier berganda digunakan untuk menghasilkan hubungan dalam bentuk numerik dan untuk melihat bagaimana variabel saling tekait.

Analisis regresi linier berganda merupakan pengembangan dari analisis regresi linier sederhana. Kegunaannya yaitu untuk meramalkan nilai variabel terikat (Y) apabila variabel bebasnya $(\mathrm{X})$ dua atau lebih. Analisis regresi linier berganda adalah alat untuk meramalkan nilai pengaruh dua variabel bebas atau lebih terhadap satu variabel terikat. Jika variabel bebas lebih dari satu, maka analisis regresi disebut regresi linear berganda. Disebut berganda karena pengaruh beberapa variabel bebas akan dikenakan kepada variabel terikat. Untuk regresi linier berganda dengan $p$ variabel bebas dapat dilihat pada persamaan, sebagai berikut :

$$
\mathrm{Y}=\mathrm{a}+\mathrm{b}_{1} \mathrm{X}_{1}+\mathrm{b}_{2} \mathrm{X}_{2 \ldots . .}+\mathrm{b}_{\mathrm{p}} \mathrm{X}_{\mathrm{p}}
$$

Keterangan :

$\mathrm{Y}=$ Variabel terikat (bangkitan/tarikan pergerakan)

a $\quad=$ Konstanta (angka yang dicari)

$\mathrm{b}_{1}, \mathrm{~b}_{2, \ldots} \ldots \mathrm{b}_{\mathrm{p}}=$ Koefisien regresi (angka yang dicari)

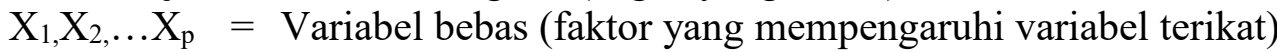

\section{PENGUMPULAN DATA}

Penelitian ini dilakukan dengan menganalisis data zona wilayah di Provinsi Kalimantan Timur yang terdiri atas 6 kabupaten yaitu Paser, Kutai Kertanegara, Berau, Kutai Barat, Kutai Timur, Penajam Paser Utara dan 3 kota yaitu Balikpapan, Samarinda, Bontang. Provinsi Kalimantan Timur terdiri atas luasan wilayah daratan $127.346,92 \mathrm{~km}^{2}$ dan luas wilayah pengelolaan laut $25.656 \mathrm{~km}^{2}$, terletak di posisi $113^{\circ} 44^{\prime}$ dan $119^{\circ} 00^{\prime}$ Bujur Timur dan antara $2^{\circ} 33^{\prime}$ Lintang Utara serta $2^{\circ} 25^{\prime}$ Lintang Selatan. Peta batas wilayah Provinsi Kalimantan Timur dapat dilihat pada Gambar 1 sebagai berikut : 


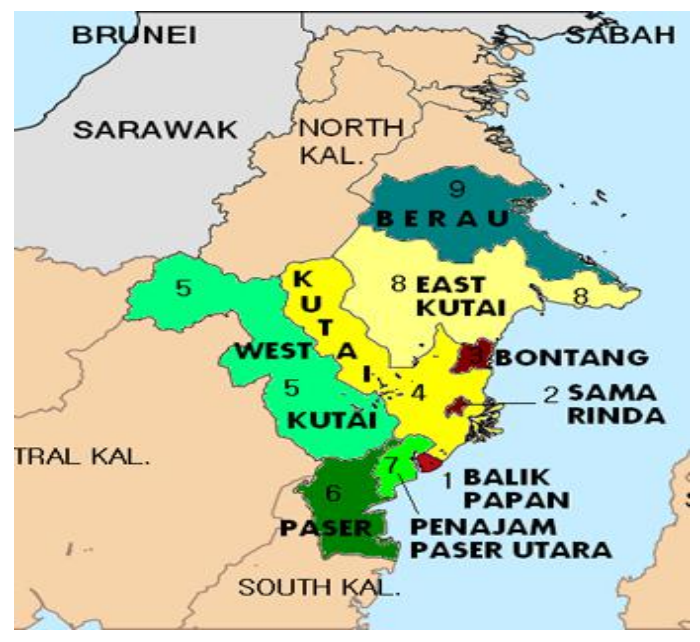

Gambar 1. Peta Wilayah Kalimantan Timur

Adapun tahapan pelaksanaan analisis dalam penelitian ini, antara lain sebagai berikut :

a. Pembagian zona dilakukan berdasarkan pengamatan pola pergerakan yang selama ini terjadi di lapangan (existing). Zona eksternal dibagi atas 3 zona yaitu :

1. Zona Eksternal 1 pergerakan asal-tujuan Provinsi Kalimantan Utara yaitu Malinau, Bulungan, Nunukan dan Tarakan.

2. Zona Eksternal 2 pergerakan asal-tujuan Provinsi Kalimantan Selatan yaitu Banjarmasin dan Kota Baru

3. Zona Eksternal 3 pergerakan asal-tujuan Kota Palu, Kota Makassar dan Kota Manado.

Sedangkan untuk zona internal dibagi atas 9 zona yaitu :

1. Zona Internal 1 yaitu Kabupaten Paser

2. Zona Internal 2 yaitu Kabupaten Kutai Kertanegara

3. Zona Internal 3 yaitu Kabupaten Berau

4. Zona Internal 4 yaitu Kabupaten Kutai Barat

5. Zona Internal 5 yaitu Kabupaten Kutai Timur

6. Zona Internal 6 yaitu Kabupaten Penajam Paser Utara

7. Zona Internal 7 yaitu Kota Balikpapan

8. Zona Internal 8 yaitu Kota Samarinda

9. Zona Internal 9 yaitu Kota Bontang.

Dalam penelitian ini, seluruh data yang akan dianalisis adalah data yang bersifat sekunder, karena data yang digunakan merupakan data yang berasal dari badan/instansi terkait. Adapun, data yang digunakan antara lain data Matriks Asal Tujuan (MAT) angkutan barang dalam Provinsi Kalimantan Timur tahun 2011 dan data sosial ekonomi Provinsi Kalimantan Timur tahun 2011.

Matriks Asal Tujuan (MAT) yang akan dianalisis, merupakan matriks dengan ukuran 12 $\mathrm{x}$ 12. Terdiri atas pergerakan 9 kabupaten/kota dalam Provinsi Kalimantan Timur serta pergerakan 3 zona eksternal. Matriks Asal Tujuan (MAT) ini selanjutnya dikonversikan ke satuan trip/tahun. Hal ini dilakukan agar dalam proses analisis Matriks Asal Tujuan (MAT) yang merupakan variabel tetap dapat dikorelasikan dengan data sosial-ekonomi yang menjadi variabel bebasnya. Proses konversi satuan ini, didasarkan pada jenis truk engkel dengan konfigurasi sumbu 1.2 yang paling sering digunakan untuk melakukan pengangkutan barang. 
Tabel 1.1. Matriks Asal Tujuan Angkutan Provinsi Kalimantan Timur Tahun 2011

\begin{tabular}{|c|c|c|c|c|c|c|c|c|c|c|c|c|c|c|}
\hline \multicolumn{2}{|c|}{ Asal Tujuan } & 1 & 2 & 3 & 4 & 5 & 6 & 7 & 8 & 9 & 10 & 11 & 12 & Jumlah \\
\hline 1 & & - & 56.163 & 5.764 & 3.759 & 8.859 & 29.854 & 88.503 & 50.717 & 6.778 & 12.883 & 40.040 & 17.500 & 320.820 \\
\hline 2 & Kertanegara & 68.166 & - & 20.983 & 22.505 & 62380 & 71.560 & 289.240 & 1.368 .245 & 78.029 & 47.200 & 94.984 & 53.489 & 2.176 .781 \\
\hline 3 & Berau & 7.493 & 30.650 & - & 2.923 & 18.000 & 7.550 & 23.546 & 48.228 & 14.908 & 68.215 & 17.723 & 21.164 & 260.400 \\
\hline 4 & $\begin{array}{l}\text { Kutai Barat } \\
\text { Kutai }\end{array}$ & 6.469 & 31.907 & 3.746 & - & 8.248 & 5.209 & 20.089 & 32.958 & 5.718 & 7.205 & 36.128 & 18.797 & 176.474 \\
\hline 5 & Timur & 12.202 & 76.687 & 20.975 & 6.601 & - & 14.684 & 66.148 & 110.866 & 72.230 & 39375 & 29.926 & 26.725 & 476.419 \\
\hline 6 & & 24.341 & 43.581 & 6.010 & 3.814 & 10.865 & . & 331.371 & 54.056 & 6.386 & 11.907 & 28.246 & 9.559 & 530.136 \\
\hline 7 & $\begin{array}{l}\text { Balikpapan } \\
\text { Kota }\end{array}$ & 62.792 & 215.189 & 26.983 & 14.119 & 37.173 & 29.5342 & - & 244.562 & 35.153 & 48.222 & 83.998 & 47.167 & 1.110 .700 \\
\hline 8 & $\begin{array}{l}\text { Samarinda } \\
\text { Kota }\end{array}$ & 50.151 & 10.21 .837 & 36.987 & 20.255 & 72.965 & 44.070 & 319.144 & - & 82.236 & 82.879 & 75.932 & 75.011 & 1.881 .467 \\
\hline 9 & Bontang & 8.553 & 50.222 & 10.557 & 3.120 & 47271 & 6.589 & 32.391 & 89.210 & - & 22.337 & 13.451 & 18.242 & 301.943 \\
\hline 10 & Exstemal I & 12.927 & 38.244 & 73.170 & 7.279 & 28.470 & 13.870 & 48.564 & 86.675 & 21.144 & - & 36.631 & 48.563 & 415.537 \\
\hline II & Fkstemal 2 & 61.301 & 97.815 & 18.899 & 40.122 & 23.652 & 39.140 & 99.163 & 153.973 & 21.347 & 43.305 & - & 265.882 & 864.599 \\
\hline 12 & Ekstemal 3 & 28.749 & 57.732 & 24.224 & 25.993 & 31.428 & 12.801 & 65.055 & 120.973 & 20.691 & 61.417 & 237.684 & - & 686.747 \\
\hline & Jumlah & 343.144 & 1.720 .027 & 248.298 & 150.490 & 349311 & 540.669 & 1383.214 & 2.360 .463 & 364.620 & 444.945 & 694.743 & 602.099 & 9.202 .023 \\
\hline
\end{tabular}

Sumber : Survei ATTN (Asal Tujuan Transportasi Nasional), Kementrian Pcrtubungan, 2011

\section{ANALISIS PENELITIAN}

\section{Matriks Asal Tujuan Provinsi Kalimantan Timur (trip/tahun)}

Berdasarkan matriks asal tujuan yang telah dianalisis, didapatkan besar bangkitan pergerakan dari angkutan barang dalam trip/tahun di Provinsi Kalimantan Timur. Besar bangkitan pergerakan angkutan barang yang terjadi dapat dilihat pada Tabel 1.2 sebagai berikut :

Tabel 1.2. Besar Bangkitan Pergerakan (Trip/Tahun) berdasarkan MAT

\begin{tabular}{clc}
\hline No & \multicolumn{1}{c}{ Zona } & $\begin{array}{c}\text { Bangkitan Pergerakan } \\
\text { (Trip/Tahun) }\end{array}$ \\
\hline 1 & Paser & 106.940 \\
2 & Kutai Kertanegara & 725.594 \\
3 & Berau & 86.800 \\
4 & Kutai Barat & 58.825 \\
5 & Kutai Timur & 158.806 \\
6 & Penajam Paser Utara (PPU) & 176.712 \\
7 & Balikpapan & 370.233 \\
8 & Samarinda & 627.156 \\
9 & Bontang & 100.648 \\
10 & Zona Eksternal 1 & 138.512 \\
11 & Zona Eksternal 2 & 288.200 \\
12 & Zona Eksternal 3 & 228.916 \\
\hline \multicolumn{2}{c}{ Jumlah } & 3.067 .342 \\
\hline \multicolumn{2}{c}{ Rata-Rata } \\
\hline
\end{tabular}




\section{Analisis Korelasi antara Variabel Sosial Ekonomi dengan Bangkitan Perjalanan}

Analisis korelasi ini, dilakukan untuk mendapatkan linear antara jumlah pergerakan dari bangkitan dan tarikan perjalanan oleh zona serta ciri sosio-ekonominya (Tamin, 2000). Dalam penelitian ini analisis korelasi yang dilakukan sebanyak 2 kali, Adapun jenis-jenis analisis korelasi yang dilakukan antara lain sebagai berikut :

a. Analisis korelasi Pearson

b. Analisis korelasi Spearman

Data sosial ekonomi yang akan dianalisis merupakan data yang berasal dari buku Kalimantan Timur dalam Angka tahun 2012 diterbitkan oleh Badan Pusat Statistik (BPS) Provinsi Kalimantan Timur yang memuat data-data sosial-ekonomi pada tahun 2011. Keseluruhan data ini dipilih berdasarkan kemungkinan adanya pengaruh data tersebut terhadap bangkitan pergerakan angkutan barang serta ketersediaan data tersebut untuk dianalisis. Adapun 20 parameter sosial ekonomi per tahun dapat dilihat pada Tabel 1.3 dan 1.4 berikut ini :

Tabel 1.3. Faktor Sosial Ekonomi Provinsi Kalimantan Timur (Tahun 2011)

\begin{tabular}{|c|c|c|c|c|c|c|c|c|c|c|c|}
\hline No & Zona & $\begin{array}{c}\text { PDRB } \\
\text { (Rupiah } \\
\text { /tahun) }\end{array}$ & $\begin{array}{c}\text { Luas } \\
\text { Wilayah } \\
\text { (ha) }\end{array}$ & $\begin{array}{c}\text { Banyak } \\
\text { Keca- } \\
\text { matan } \\
\text { (Keca } \\
\text { matan) }\end{array}$ & $\begin{array}{c}\text { Jumlah } \\
\text { Pen- } \\
\text { duduk } \\
\text { (orang) }\end{array}$ & $\begin{array}{l}\text { Produksi } \\
\text { Padi } \\
\text { Sawah } \\
\text { (Ton } \\
\text { /tahun) }\end{array}$ & $\begin{array}{l}\text { Produksi } \\
\text { Ubi } \\
\text { Jalar } \\
\text { (Ton } \\
\text { /tahun) }\end{array}$ & $\begin{array}{l}\text { Produksi } \\
\text { Kacang } \\
\text { Tanah } \\
\text { (Ton } \\
\text { /tahun) }\end{array}$ & $\begin{array}{c}\text { Produksi } \\
\text { Kacang } \\
\text { Hijau } \\
\text { (Ton } \\
\text { /tahun) }\end{array}$ & $\begin{array}{c}\text { Produksi } \\
\text { Kedelai } \\
\text { (Ton } \\
\text { /tahun) }\end{array}$ & $\begin{array}{c}\text { Produksi } \\
\text { Jagung } \\
\text { (Ton } \\
\text { /tahun) }\end{array}$ \\
\hline & & X1 & $\mathrm{X} 2$ & X3 & $\mathrm{X} 4$ & X5 & X6 & $X 7$ & X8 & X9 & $\mathrm{X} 10$ \\
\hline 1 & $\begin{array}{l}\text { Paser } \\
\text { Kutai }\end{array}$ & 16.680 .292 & 1.119 .293 & 10 & 239.221 & 26.336 & 1446 & 112 & 54 & 155 & 529 \\
\hline 2 & Kertanegara & 51.946 .367 & 2.634 .895 & 18 & 650.908 & 198.023 & 6864 & 712 & 285 & 541 & 2.015 \\
\hline 3 & Berau & 9.607 .427 & 2.220 .033 & 13 & 186.003 & 16.559 & 1605 & 358 & 120 & 606 & 1.315 \\
\hline 4 & $\begin{array}{l}\text { Kutai Barat } \\
\text { Kutai }\end{array}$ & 8.083 .976 & 3.094 .560 & 21 & 171.474 & 5.423 & 2133 & 93 & 58 & 31 & 396 \\
\hline 5 & $\begin{array}{l}\text { Timur } \\
\text { Penajam }\end{array}$ & 44.900 .229 & 3.189 .649 & 18 & 265.521 & 19.854 & 1.732 & 202 & 68 & 299 & 1.117 \\
\hline 6 & Paser Utara & 2.615 .470 & 321.115 & 4 & 148.448 & 64.081 & 1.162 & 38 & 19 & 14 & 105 \\
\hline 7 & Balikpapan & 22.882 .880 & 56.128 & 5 & 579.137 & 997 & 165 & 6 & 0 & 0 & 665 \\
\hline 8 & Samarinda & 27.352 .115 & 71.783 & 10 & 755.628 & 15.012 & 317 & 15 & 4 & 6 & 50 \\
\hline 9 & Bontang & 9.543 .417 & 19.256 & 3 & 149.239 & 245 & 134 & 2 & 0 & 0 & 7 \\
\hline 10 & Eksternal 1 & 16.542 .821 & 6.756 .918 & 41 & 529.151 & 80.667 & 2.338 & 274 & 153 & 620 & 943 \\
\hline 11 & Eksternal 2 & 10.511 .542 & 949.540 & 25 & 931.977 & 65.663 & 5.063 & 1,172 & 314 & 2.514 & 20.491 \\
\hline 12 & Eksternal 3 & 89.260 .704 & 73.818 & 27 & 2.110 .004 & 15.489 & 1.700 & 345 & 34 & 0 & 5.969 \\
\hline
\end{tabular}


Tabel 1.4. Faktor Sosial Ekonomi Provinsi Kalimantan Timur (Tahun 2011)

\begin{tabular}{|c|c|c|c|c|c|c|c|c|c|c|c|}
\hline No & Zona & $\begin{array}{c}\text { Produksi } \\
\text { Kelapa } \\
\text { Sawit } \\
\text { (Ton } \\
\text { /tahun) }\end{array}$ & $\begin{array}{l}\text { Produksi } \\
\text { Telur } \\
\text { (Ton } \\
\text { /tahun) }\end{array}$ & $\begin{array}{l}\text { Ternak } \\
\text { Ayam } \\
\text { (Ekor) }\end{array}$ & $\begin{array}{c}\text { Ternak } \\
\text { Kambing } \\
\text { (Ekor) }\end{array}$ & $\begin{array}{l}\text { Ternak } \\
\text { Sapi } \\
\text { (Ekor) }\end{array}$ & $\begin{array}{l}\text { Produksi } \\
\text { Perika- } \\
\text { nan Laut } \\
\text { (Ton } \\
\text { /tahun) }\end{array}$ & $\begin{array}{c}\text { Produksi } \\
\text { Tambak } \\
\text { Air } \\
\text { Payau } \\
\text { (Ton } \\
\text { /tahun) }\end{array}$ & $\begin{array}{c}\text { Jumlah } \\
\text { Rumah } \\
\text { Sakit } \\
\text { (RS) }\end{array}$ & $\begin{array}{c}\text { Banyak } \\
\text { Kamar } \\
\text { Hotel } \\
\text { Berbin- } \\
\text { tang } \\
\text { (kamar) }\end{array}$ & $\begin{array}{l}\text { Pan- } \\
\text { jang } \\
\text { Jalan } \\
\text { Ber- } \\
\text { aspal } \\
(\mathrm{Km})\end{array}$ \\
\hline & & X11 & $\mathrm{X} 12$ & X 13 & $\mathrm{X} 14$ & $\times 15$ & X16 & X17 & $\mathrm{X} 18$ & X19 & $\times 20$ \\
\hline 1 & $\begin{array}{l}\text { Paser } \\
\text { Kutai }\end{array}$ & 918.679 & 252 & 2.050 .000 & 4.847 & 12.189 & 10.009 & 3.669 & 1 & 465 & 223 \\
\hline 2 & Kertanegara & 323.248 & 6.338 & 9.548 .925 & 6.828 & 23.464 & 31.463 & 7.672 & 2 & 784 & 361 \\
\hline 3 & Berau & 275.951 & 106 & 1.748 .238 & 7.163 & 8.426 & 15.510 & 936 & 1 & 866 & 247 \\
\hline 4 & Kutai Barat & 159.601 & 190 & 153,348 & 5,462 & 6.236 & 0 & 0 & 1 & 752 & 185 \\
\hline 5 & $\begin{array}{l}\text { Kutai Timur } \\
\text { Penajam }\end{array}$ & 1.889 .599 & 0 & 1.821 .500 & 6.977 & 15.022 & 5.669 & 437 & 6 & 1.563 & 312 \\
\hline 6 & Paser Utara & 513.640 & 407 & 35.191 & 4.982 & 10.440 & 4.447 & 5.091 & 2 & 179 & 59 \\
\hline 7 & Balikpapan & 0 & 490 & 9.519 .240 & 2.087 & 1.652 & 6.386 & 248 & 12 & 2.549 & 46 \\
\hline 8 & Samarinda & 1.064 & 1.661 & 8.640 .860 & 12.635 & 5.681 & 8.768 & 0 & 13 & 2.919 & 52 \\
\hline 9 & Bontang & 0 & 41 & 1.781 .200 & 358 & 501 & 8.512 & 81 & 4 & 866 & 9 \\
\hline 10 & Eksternal 1 & 389.764 & 464 & 3.133 .985 & 10.005 & 14.372 & 11.872 & 8.387 & 6 & 2.044 & 624 \\
\hline 11 & Eksternal 2 & 0 & 0 & 14.492 .901 & 13.546 & 8.461 & 48.602 & 12.057 & 12 & 5.036 & 776 \\
\hline 12 & Eksternal 3 & 0 & 2.056 & 4.795 .645 & 9.047 & 5.251 & 23.319 & 661 & 37 & 7.432 & 1.389 \\
\hline
\end{tabular}

Berdasarkan nilai koefisien korelasi (r) dari hasil analisis yang dilakukan sebanyak dua kali yaitu dengan metode pearson dan metode spearman, maka variabel bebas yang memiliki korelasi cukup besar untuk selanjutnya digunakan dalam membangun Model berbasis Regresi Linear berganda untuk bangkitan adalah PDRB, Ternak Ayam, Produksi Padi Sawah, Ternak Kambing, Produksi Telur dan Produksi Perikanan Laut. Berikut adalah hasil rekapitulasi nilai $\mathrm{r}$ dari variabel bebas untuk bangkitan pergerakan. 
Tabel 1.5. Rekapitulasi Nilai r beserta Peringkatnya untuk Bangkitan Pergerakan

\begin{tabular}{clccc}
\hline X-n & \multicolumn{1}{c}{ Variabel Bebas } & Peringkat & Nilai r Pearson & Nilai r Spearman \\
\hline X13 & Ternak Ayam & 1 & 0,6385 & 0,7830 \\
X12 & Produksi Telur & 2 & 0,7265 & 0,5790 \\
X1 & PDRB & 3 & 0,3309 & 0,6220 \\
X5 & Produksi Padi Sawah & 4 & 0,5239 & 0,2870 \\
X16 & Produksi Perikanan Laut & 5 & 0,3362 & 0,3710 \\
X14 & Ternak Kambing & 6 & 0,3001 & 0,2940 \\
X4 & Jumlah Penduduk & 7 & 0,2791 & 0,7060 \\
X18 & Jumlah Rumah Sakit & 8 & 0,1500 & 0,6450 \\
X19 & Banyak Kamar Hotel Berbintang & 9 & 0,1442 & 0,4460 \\
X6 & Produksi Ubi Jalar & 10 & 0,3883 & 0,1050 \\
X15 & Ternak Sapi & 11 & 0,3001 & 0,1120 \\
X2 & Luas Wilayah & 12 & $-0,1870$ & $-0,2940$ \\
X11 & Produksi Kelapa Sawit & 13 & $-0,2302$ & $-0,1920$ \\
X7 & Produksi Kacang Tanah & 14 & 0,2416 & 0,1400 \\
X17 & Produksi Tambak Air Payau & 15 & 0,1740 & 0,2120 \\
X10 & Produksi Jagung & 16 & 0,0626 & 0,2800 \\
X8 & Produksi Kacang Hijau & 17 & 0,2823 & 0,0050 \\
X20 & Panjang Jalan Beraspal & 18 & $-0,0365$ & 0,1470 \\
X9 & Produksi Kedelai & 19 & 0,0564 & $-0,0840$ \\
X3 & Banyak Kecamatan & 20 & $-0,0790$ & 0,0140 \\
\hline
\end{tabular}

\section{Analisa Regresi Linier Berganda untuk Mendapatkan Persamaan Model Bangkitan}

Analisis regresi linier berganda digunakan untuk meramalkan suatu variabel terikat bangkitan (Y) berdasarkan variabel-variabel bebas yang lolos dalam analisis korelasi dalam suatu persamaan linier. Untuk mendapatkan model yang paling sesuai menggambarkan pengaruh suatu atau beberapa variabel bebas terhadap variabel terikat digunakan analisis regresi berganda (Multiple Linear Regresion Analysis). Dengan metode analisis langkah demi langkah akan dicari model terbaik yang paling tepat dalam mencerminkan realita yang ada. Analisis yang dilakukan adalah dengan perhitungan manual serta dengan menggunakan bantuan software SPSS 22.

Berdasarkan hasil analisis regresi linier berganda yang dilakukan dapat dilakukan proses penentuan model dengan metode langkah-demi langkah tipe 1 sesuai dengan prosedur yang ada. Hasil pemodelan bangkitan pergerakan dapat dilihat pada Tabel 1.6, sebagai berikut . 
Tabel 1.6. Hasil Pemodelan Bangkitan Pergerakan Angkutan Barang

\begin{tabular}{|c|c|c|c|c|c|c|c|c|c|}
\hline \multirow{2}{*}{ No } & \multirow{2}{*}{ Peubah } & \multirow{2}{*}{$\begin{array}{c}\text { Tanda } \\
\text { yang } \\
\text { diharap } \\
\text { kan }\end{array}$} & \multirow{2}{*}{$\begin{array}{l}\text { Parame } \\
\text { ter } \\
\text { Model }\end{array}$} & \multicolumn{6}{|c|}{ Tahap } \\
\hline & & & & 1 & 2 & 3 & 4 & 5 & 6 \\
\hline 1 & Intersep & $+/-$ & $\mathrm{C}$ & $77.041,534$ & $115.835,492$ & $137.912,655$ & $92.513,009$ & $75.830,865$ & $98.689,626$ \\
\hline 2 & PDRB & + & $\mathrm{X}_{1}$ & $-0,001$ & $-0,001$ & $-0,002$ & $-0,001$ & - & - \\
\hline \multirow[t]{2}{*}{3} & Produksi & & & & & & & & \\
\hline & $\begin{array}{l}\text { Padi } \\
\text { Sawah }\end{array}$ & + & $\mathrm{X}_{5}$ & $-0,397$ & $-0,080$ & $-1,488$ & - & - & - \\
\hline 4 & $\begin{array}{l}\text { Produksi } \\
\text { Telur }\end{array}$ & + & $\mathrm{X}_{12}$ & 102,167 & 87,688 & 126,352 & 81,366 & 74,369 & - \\
\hline 5 & $\begin{array}{l}\text { Ternak } \\
\text { Ayam }\end{array}$ & + & $\mathrm{X}_{13}$ & 0,035 & 0,038 & 0,023 & 0,022 & 0,022 & 0,033 \\
\hline 6 & $\begin{array}{l}\text { Ternak } \\
\text { Kambing }\end{array}$ & + & $\mathrm{X}_{14}$ & 11,399 & - & - & - & - & - \\
\hline \multirow[t]{4}{*}{7} & $\begin{array}{l}\text { Produksi } \\
\text { Perikana } \\
\text { n Laut }\end{array}$ & + & $\mathrm{X}_{16}$ & $-8,407$ & $-7,634$ & - & - & - & - \\
\hline & & $\mathrm{R}$ & & 0,977 & 0,963 & 0,930 & 0,908 & 0,904 & 0,697 \\
\hline & & $\mathrm{R}^{2}$ & & 0,954 & 0,928 & 0,865 & 0,825 & 0,817 & 0,485 \\
\hline & & iitung & & 17,311 & 15,532 & 11,253 & 12,534 & 20,099 & 9,425 \\
\hline
\end{tabular}

Berdasarkan pertimbangan dan ketentuan dalam memilih model terbaik, maka peneliti memilih pemodelan 1, karena memiliki nilai koefisien korelasi, nilai koefisien determinasi serta nilai f hitung yang tertinggi dibandingkan dengan model yang lain. Maka kesimpulannya untuk tahap ini, model terbaik yang dapat mencerminkan realita yang ada adalah :

$$
\begin{aligned}
& Y=77.041,534-0,001 X_{1}-0,397 X_{5}+102,167 X_{12}+0,035 X_{13}+11,399 X_{14}-8,407 X_{16} \\
& R^{2}=0,954
\end{aligned}
$$

Keterangan :

$$
\begin{aligned}
& \mathrm{Y}=\text { Bangkitan pergerakan (trip/tahun) } \\
& \mathrm{X}_{1}=\text { PDRB (rupiah/tahun) } \\
& \mathrm{X}_{5}=\text { Produksi Padi Sawah (ton/tahun) } \\
& \mathrm{X}_{12}=\text { Produksi Telur (ton/tahun) } \\
& \mathrm{X}_{13}=\text { Ternak Ayam (ekor) } \\
& \mathrm{X}_{14}=\text { Ternak Kambing (ekor) } \\
& \mathrm{X}_{16}=\text { Produksi Perikanan Laut (ton/tahun) } \\
& \mathrm{R}^{2}=\text { Koefisien Determinasi }
\end{aligned}
$$

\section{Uji Verifikasi Model Bangkitan Pergerakan terhadap MAT (Matriks Asal Tujuan)}

Dari model terbaik yang didapatkan, akan diuji verifikasi satu per satu hasil atau jumlah perjalanan dari setiap zona berdasarkan model yang didapatkan. Dimana hasil dari matriks survei ATTN (Asal Tujuan Transportasi Nasional) dapat menjadi tolak ukur atau dasar dalam memilih model yang dianggap merupakan model bangkitan atau model tarikan yang terbaik. Dengan kata lain untuk membuktikan apakah hasil dari permodelan sesuai dengan fakta perjalanan atau trip di lapangan.

Untuk verifikasi model bangkitan pada masing-masing zona pergerakan disajikan dalam bentuk grafik yang dapat dilihat pada Gambar 2 dan Tabel 1.7 sebagai berikut. 


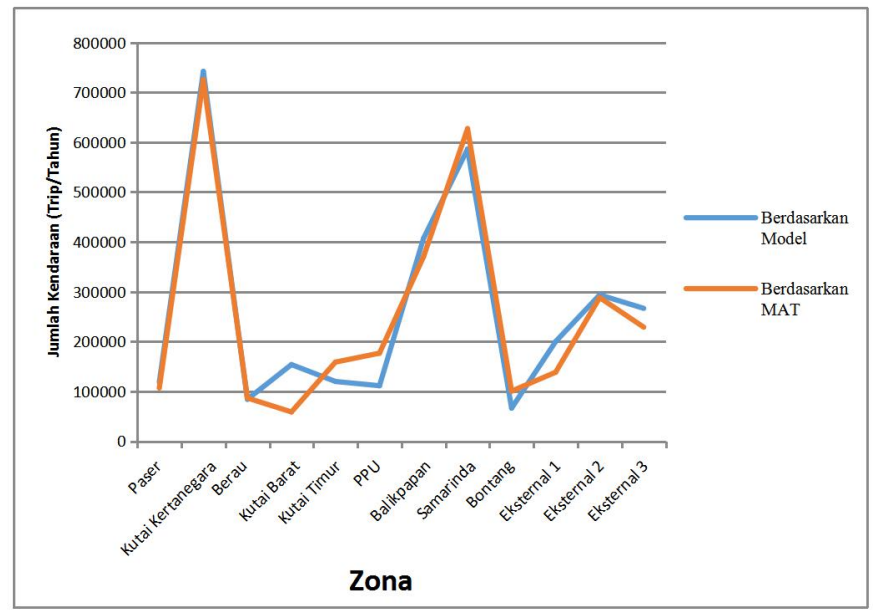

Gambar 2. Grafik Verifikasi Model Bangkitan

Tabel 1.7. Besar Bangkitan Pergerakan berdasarkan Model dan MAT

\begin{tabular}{clccc}
\hline No & \multicolumn{1}{c}{ Zona } & Model (Trip/Tahun) & $\begin{array}{c}\text { MAT } \\
\text { (Trip/Tahun) }\end{array}$ & $\begin{array}{c}\text { Selisih } \\
\mathbf{( \% )}\end{array}$ \\
\hline 1. & Paser & 118.586 & 106.940 & 9,82 \\
2. & Kutai Kertanegara & 742.144 & 725.594 & 2,23 \\
3. & Berau & 84.186 & 86.800 & 3,11 \\
4. & Kutai Barat & 153.861 & 58.825 & 61,77 \\
5. & Kutai Timur & 119.943 & 158.806 & 32,40 \\
6. & Penajam Paser & 111.396 & 176.712 & \\
& Utara & 407.104 & 370.233 & 58,63 \\
7. & Balikpapan & 586.217 & 627.156 & 6,06 \\
8. & Samarinda & 66.452 & 100.648 & 51,46 \\
9. & Bontang & 200.049 & 138.512 & 30,76 \\
10. & Eksternal 1 & 293.724 & 288.200 & 1,88 \\
11. & Ekternal 2 & 266.665 & 228.916 & 14,16 \\
12. & Eksternal 3 & & & \\
\hline
\end{tabular}

\section{KESIMPULAN}

\section{Kesimpulan}

Berdasarkan hasil analisis data dalam penelitian ini, maka didapatkan kesimpulan sebagai berikut :

1. Faktor-faktor yang mempengaruhi terjadinya bangkitan angkutan barang dalam Provinsi Kalimantan Timur Tahun 2011 antara lain PDRB sebagai $X_{1}$, Produksi Padi Sawah sebagai $\mathrm{X}_{5}$, Produksi Telur sebagai $\mathrm{X}_{12}$, Ternak Ayam sebagai $\mathrm{X}_{13}$, Ternak Kambing sebagai $\mathrm{X}_{14}$ dan Produksi Perikanan Laut sebagai $\mathrm{X}_{16}$.

2. Faktor-faktor yang mempengaruhi terjadinya bangkitan angkutan barang dalam Provinsi Kalimantan Timur Tahun 2011 antara lain PDRB sebagai $X_{1}$, Produksi Padi Sawah sebagai $\mathrm{X}_{5}$, Produksi Telur sebagai $\mathrm{X}_{12}$, Ternak Ayam sebagai $\mathrm{X}_{13}$, Ternak Kambing sebagai $\mathrm{X}_{14}$ dan Produksi Perikanan Laut sebagai $\mathrm{X}_{16}$.

3. Berdasarkan model bangkitan di atas, hasil estimasi/perkiraan jumlah bangkitan perjalanan yang dibangkitkan oleh pergerakan angkutan barang dalam provinsi Kalimantan Timur 
pada tahun 2017 (pada masa penelitian) adalah untuk zona Paser sebesar 158.917 trip/tahun, zona Kutai Kertanegara sebesar 994.544 trip/tahun, zona Berau sebesar 112.817 trip/tahun, zona Kutai Barat sebesar 206.189 trip/tahun, zona Kutai Timur sebesar 160.735 trip/tahun, zona Penajam Paser Utara (PPU) sebesar 149.281 trip/tahun, zona Balikpapan sebesar 545.558 trip/tahun, zona Samarinda sebesar 785.587 trip/tahun, zona Bontang sebesar 89.052 trip/tahun, zona eksternal 1 sebesar 268.085 trip/tahun, zona eksternal 2 sebesar 393.618 trip/tahun dan zona eksternal 3 sebesar 357.357 trip/tahun.

\section{Saran}

Berdasarkan hasil dari penelitian yang telah dilakukan, maka penulis merekomendasikan saran sebagai berikut :

1. Perlu dilakukan penelitian lebih lanjut untuk menganalisis faktor-faktor yang mempengaruhi bangkitan pergerakan angkutan barang dalam provinsi Kalimantan Timur dengan menggunakan MAT (Matrik Asal Tujuan) tahun 2016.

2. Untuk penelitian selanjutnya diharapkan agar faktor-faktor yang menyebabkan terjadinya bangkitan pergerakan yang dianalisis lebih banyak lagi, agar jumlah pergerakan hasil dari MAT (Matrik Asal Tujuan) dengan jumlah pergerakan hasil dari model lebih akurat mendekatan keadaan real di lapangan.

3. Pada saat proses konversi satuan, lebih baik dilakukan survey lalu-lintas terlebih dahulu di setiap zona agar dalam penentuan jenis truk yang paling sering melintas menggunakan data yang kongkrit.

4. Hasil dari penelitian ini akan lebih baik jika dilanjutkan pada tahap perencanaan sarana dan prasarana transportasi agar mendapatkan solusi atau menghindari adanya permasalahan yang terjadi akibat bangkitan lalu lintas pergerakan angkutan barang.

\section{DAFTAR PUSTAKA}

Amijaya, Jimi \& Suprayitno, H. (2018). "Permodelan Bangkitan dan Tarikan Perjalanan Moda Sepeda Motor di Wilayah Perkotaan Gresik Tahun 2018”. Jurnal Manajemen Aset Infrastruktur \& Fasilitas, Vol 2, Suplemen 2, Desember 2018, Hal. : 01-10.

BPS KalTim (2012). Kalimantan Timur Dalam Angka 2012. Badan Pusat Statistik. Provinsi Kalimantan Timur. Samarinda.

Anggita, C., Arifin, T.S.P. \& Dhonanto, D. (2015). "Master Plan Road Network in The Border Region of Nunukan Regency of The North Kalimantan Province". Universitas Lampung. Lampung.

Dhonanto, D., Arifin, T.S.P. \& Anggita, C. (2015). "Masterplan Road Network in The Border Region of Malinau Regency of The North Kalimantan Province”. Institut Teknologi Bandung. Bandung.

DisHub KalTim (2014). Studi Master Plan Jaringan Kereta Api (KA) Provinsi Kalimantan Timur. Dinas Perhubungan Provinsi Kalimantan Timur.

Irianto, Agus (2014). Statistik Konsep Dasar, Aplikasi dan Pengembangannya. Kencana Prenadamedia Group. Jakarta.

Jogiyanto (2005). Analisis dan Desain Sistem Informasi. Penerbit Andi. Yogyakarta.

Kodoatie, Robert J. (2005). Analisis Ekonomi Teknik. Penerbit Andi. Yogyakarta.

Miro, Fidel (2005). Perencanaan Transportasi untuk Mahasiswa, Perencana dan Praktisi. Erlangga. Jakarta.

Misbahudin \& Hasan, Iqbal (2013). Analisis Data Penelitian dengan Statistik. Bumi Aksara. Jakarta.

Morlok, Edward K. (1984). Pengantar Teknik dan Perencanaan Transportasi. Erlangga. Jakarta. 
Mutiawati, Cut \& Suprayitno, H. (2018). "Tinjauan Awal Struktur Jaringan Jalan di Kota Banda Aceh". Jurnal Manajemen Aset Infrastruktur \& Fasilitas. Vol 2, Suplemen 2, Desember 2018, Hal. : 39-52.

Ortuzar, J.D. \& Willumsen, L.G. (1994). Modelling Transport. John Wiley \& Sons. Canada.

Praditya, N.D.A. \& Suprayitno, H. (2018). "Model Bangkitan Perjalanan Kota Samarinda Berbasis Zona Kecamatan". LPPM Universitas Pelita Harapan. Surabaya.

Riduwan \& Akdon (2006). Rumus dan Data dalam Aplikasi Statistika. Alfabeta. Bandung. Sugiyono (2011). Metode Penelitian Kuantitatif, Kualitatif dan R \& D. Alfabeta. Bandung.

Suprayitno, H. (1999). "Metoda Pemodelan Kebutuhan Angkutan Barang Perkotaan - Kasus Kota Surabaya". Prosiding Simposium FSTPT, Vol.2.

Suprayitno, H. \& Ratnasari, V. (2017). "Reflexion on Linear Regression Trip Production Modelling Method for Ensuring Good Model Quality". AIP Conference Proceedings 1903 (1), 060013, 2017.

Suprayitno, H. \& Soemitro, R.A.A. (2018). "Preliminary Reflexion on Basic Principle of Infrastructure Asset Management". Jurnal Manajemen Aset Infrastruktur \& Fasilitas, Vol. 2, No. 1, Maret 2018, Hal. : 1-9.

Tamin, O.Z, (2000). Perencanaan dan Permodelan Transportasi. ITB. Bandung. Usman, Husein \& Akbar, Purnomo (2008). Pengantar Statistika, Bumi Aksara. Jakarta.

Ziantono, Dio H. \& Suprayitno, H. (2018). "Studi Hubungan antara Koefisien Determinasi dengan Kesalahan Prediksi untuk Ukuran Sampel Tertentu pada Model Bangkitan Perjalanan di Wilayah Perkotaan Gresik". Jurnal Manajemen Aset Infrastruktur \& Fasilitas, Vol 2, No 2, September 2018, Hal. : 99-110. 